\title{
ENFOQUE COMUNITARIO, MODERNIDAD Y POSTMODERNIDAD. EL TRABAJO SOCIAL CON LA COMUNIDAD EN TIEMPOS DE LA GLOBALIZACIÓN
}

\section{CLARISA RAMOS FEIJÓO}

Profesora Asociada del Departamento de Trabajo Social y Servicios Sociales. EUTS Universidad de Alicante.

«La realidad inteligente, sí señor. Todos soltamos un hilo, como gusanos de seda. Roemos y nos disputamos las hojas de morera pero ese hilo, si se entrecruza con otros, si se entrelaza, puede hacer un hermoso tapiz, una tela inolvidable» Manuel Rivas, O lapis do carpinteiro

\section{RESUMEN}

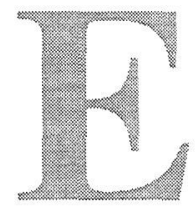

lenfoque comunitario requiere por su propia definición la existencia de la comunidad. Nos planteamos entonces, como cuestionamiento metodológico, la aparente contradicción que existe entre, por una parte, la comunidad tradicional y, por otra, el objetivo del Trabajo Social Comunitario. Aquella es una figura premoderna y el Trabajo Social conlleva, por su filosofía y método, una orientación hacia la modernización de las conductas y las relaciones.

El presente artículo analiza, desde la lectura de los clásicos de la Sociología, las diferencias epistemológicas que confrontan los conceptos de comunidad y sociedad, dando paso a un análisis del Trabajo Social en el contexto de la globalización y la complejidad de la realidad social. Busca, asimismo, recuperar las experiencias de enfoque comunitario, desarrolladas en España y también en otros contextos, para promover el análisis que conduzca a la construcción de nuevas formas de intervención comunitarias.

En tal sentido, la propuesta es conciliar las figuras de comunidad, referente del Trabajo Social Comunitario y la de sociedad referente para este análisis del Trabajo Social.

Palabras clave: Trabajo Social con la comunidad, comunidad, sociedad, modernidad, postmodernidad, globalización. 


\section{INTRODUCCIÓN}

Partimos de considerar que el enfoque comunitario tiene, como cualquier otro enfoque del Trabajo Social, el objetivo de mejorar las condiciones de vida de los usuarios y seguidamente afirmamos que existe la tendencia a identificar mejora con desarrollo, es decir, indicadores de modernidad. Sin embargo, el enfoque comunitario necesita, por definición, de la comunidad, pero veremos que en la historia de la Sociología, la comunidad ha sido definida como una estructura basada en los afectos y el conocimiento directo (premoderna), mientras que la sociedad, con sus características de organización, es la que confiere rasgos de modernidad, lo que en principio parecería conducir a una contradicción metodológica.

Pero si aterrizamos en el planteamiento, deberíamos asumir que nos encontramos en este momento con la coexistencia de múltiples relaciones de integración social. Casi podríamos decir que un sesgo de la postmodernidad tiene que ver con esa multiplicidad de formas de convivencia y de solidaridad social, que relacionamos con lo que Edgar Morin ha definido como complejidad.

¿Cómo se concilia esta realidad desde nuestra ética profesional a la hora de intervenir? Analizaremos algunos ejemplos de casos en que la realidad demuestra un choque de intereses entre la población y los que llevan iniciativas de desarrollo.

¿Cómo se concilia el binomio conceptual "comunidad-sociedad" en la intervención desde el Trabajo Social?

Cuando hablamos de las nuevas formas de intervención: ¿cuál es la fuente conceptual de la que se nutren las nuevas formas de intervención? ¿En qué medida han influido las políticas de la Unión Europea en el Trabajo Social Comunitario?

En el marco de la globalización y las nuevas tecnologías nos hacemos eco de la necesidad de un nuevo discurso para una sociedad cada vez más compleja: ¿estamos ante una nueva reconceptualización del Trabajo Social? ¿Se materializará esta vez en nuevas formas de intervención?

La nuevas formas de intervención leídas desde el Pensamiento Complejo abren grandes posibilidades al Trabajo Social Comunitario. Es posible intervenir desde expectativas comunitarias en una sociedad postmoderna, pero para hacerlo es preciso ser conscientes y conocedores de los fundamentos de nuestra intervención. Y para poder saber desde dónde y hacia dónde vamos en el campo del Trabajo Social con la comunidad es, a nuestro criterio, necesario asumir que las nuevas 
formas de intervención sólo se entienden desde el análisis de la historia del Trabajo Social Comunitario que se realizaba hace ya 30 años, y la perspectiva histórica que en ello radica.

\section{SOCIEDAD, COMUNIDAD ¿UNA PAREJA DESAVENIDA?}

Las diferentes acepciones de comunidad y sociedad por las que se establecen sus diferencias conceptuales forman parte de la historia misma de las Ciencias Sociales. En muchos casos sus propias definiciones han generado incomodidades conceptuales, dado que no encajaban con los argumentos utilizados en la intervención comunitaria. Desde su propia esencia, el hombre es un ser social que a lo largo de la historia ha buscado la solución a sus problemas y necesidades asociándose.

La lectura de los clásicos nos muestra la larga trayectoria del binomio que viene siendo definido por contraposición a la vez que reconocido como continuidad y simultaneidad. En La Ciudad de Dios, San Agustín distinguía entre comunidad y sociedad como los dos tipos principales de sociabilidad existentes.

Spencer también hace referencia a estas dos posibilidades al describir los rasgos de la sociedad militar y la sociedad industrial. Durkheim establece la división entre solidaridad mecánica, en la que se distinguen la semejanza de afectos y creencias, y la solidaridad orgánica visible en las sociedades con gran división del trabajo. Weber toma directamente de Durkheim esta dicotomía y habla de tradición y de racionalidad.

Charles Cooley define dos tipos de grupos, los primarios, a los que da el nombre de comunidades, y los secundarios, en los que involucra lo que conocemos bajo el concepto de sociedad.

Por su parte, la Sociología marxista conceptualiza la comunidad como una unión de individuos que viven en un mismo territorio ligado por intereses, actividades y objetivos comunes, siempre vinculados a relaciones materiales que se concretan en el proceso de trabajo y reciben mediación del mismo.

El clásico que con mayor detenimiento ha desarrollado estos temas ha sido el alemán Tönnies, que ha determinado visiblemente todo el debate intelectual sobre la dicotomía entre sociedad y comunidad. Tönnies distingue entre la Gemeinschaft (relación social real y orgánica o comunidad), como lo identificado con las relaciones familiares, los afectos, y la Gesellschaft (relación social imaginaria y mecánica o asociación) como lo vinculado a las relaciones secundarias y forma- 
les. La Cultura de la Comunidad en sustitución de la Civilización de la Asociación dirá este autor alemán. En 1931, Tönnies definiría Gemeinschaft como «todas las clases y asociaciones en las cuales predomina la voluntad natural» y Gessellschaft a «las formadas o condicionadas fundamentalmente por la voluntad racional» (Sorokin P. 178). Talcott Parsons situó lo que llamó la «clave de la Gessellschaft» en «la búsqueda racional del propio interés individual» (Parsons: 837).

Pitirim A. Sorokin habla de las relaciones de tipo familístico y las de tipo mixto o contractual. Sorokin reconoce la teoría de Tönnies como una de las más fecundas, sin embargo, encuentra que en ella reside la fuente de grandes defectos lógicos, como, entre otros, el sostener un proceso evolutivo desde la Gemeinschaft hacia la Gessellschaft, ya que es verificable que ambas han coexistido.

Por su parte, Max Scheller distinguió cuatro formas que serían subdivisiones de las definidas por Tönnies, en una línea de investigación semejante se situó Lavrov. R.M. MacIver definió a la comunidad como claramente opuesta a la asociación. El signo distintivo de la comunidad radica, según este autor, en que la vida de cada individuo puede ser vivida totalmente dentro de la comunidad, a la que vincula siempre con un área territorial.

Gurvitch sostiene que mientras la sociedad tiene una presencia estructural objetivada, la comunidad responde a la realidad psicosocial (Badi; B. 1990: 95-115).

Por su parte, el filósofo español, José Luis Aranguren, describe a la comunidad y a la sociedad como tipos ideales que no existen en estado puro, sino que más bien diríamos nosotros «coexisten», sin embargo, Aranguren continuaba diciendo que el problema consiste en que las frías relaciones impuestas por la sociedad nos llevan a echar en falta los vínculos del afecto.

El propio Salvador Giner hace también la salvedad de que comunidad y asociación son dos tipos ideales, dos variedades de grupos humanos que «rara vez se encuentran concretamente en estado puro» (1985:87). En su análisis, Giner describe la existencia de dos tipos de formaciones sociales:

1) las basadas en vínculos afectivos donde cada integrante ve al otro como un fin en sí mismo, y existe un conocimiento directo y profundo del otro (comunidades),

2) las basadas en fines utilitarios donde los demás integrantes son percibidos como medios para lograr un fin. El conocimiento es de tipo superficial (grupos secundarios, asociaciones, sociedades). 
El criterio de diferenciación señalado por Giner entre los conceptos de sociedad y comunidad es un criterio de grado, dependiendo de la prevalencia del factor afectivo en las relaciones.

Así podríamos trazar un mapa conceptual en el que siempre se ha distinguido a la comunidad como el aspecto gregario vinculado a los afectos y las relaciones interpersonales y a la sociedad como aquello que se relaciona con aspectos de racionalidad y modernidad.

Podríamos entonces afirmar que existe una necesidad en las sociedades modernas de retornar a lo comunitario en su sentido más primario, como respuesta a las frustraciones que genera una sociedad moderna donde no se llegan a satisfacer las necesidades básicas y que aun cuando éstas se satisfacen se crean otras nuevas necesidades vinculadas incluso a aspectos inmateriales (comunicación, afecto, compañía).

En este sentido, hemos considerado conveniente el entender estos conceptos desde una estructura de matriz, donde quede reflejada la complejidad de la realidad social. Esto requiere intervenciones que, si bien de manera indudable deban tender a una modernización, o progreso, entendidos como forma de satisfacción de necesidades de las personas, no dejen de lado los aspectos más vinculados a las relaciones interpersonales del ámbito comunitario. Consideramos ilustrativa la imagen que define a la comunidad como un entramado, ya que refleja claramente la fusión y diversidad de variables que intervienen y que determinan la realidad social.

Casi podría decirse que queremos comunidad y sociedad a la vez. Otra cosa es que realmente se logre y, mucho más aún, otra cosa es que las estrategias realmente propicien lo que las ciencias sociales han definido, de manera más o menos ambigua, como comunitario.

Comunidad es, por tanto, un concepto que se encuentra sujeto a diversas revisiones. En nuestro entorno, profesional, temporal y geográfico encontramos opiniones como las del profesor Josep Canals, que mantiene sus reservas hacia el «uso acrítico del concepto de comunidad» (Canals, J. 1997:35). Entre otros, se basa en argumentos como el del trabajo clásico de Hillery (1955) donde, tras analizar 94 definiciones de comunidad, alcanzó la conclusión de que «aparte del concepto de que la gente vive en comunidad, no existe un acuerdo total referente a la naturaleza de la comunidad».

Se contraponen también, en el análisis de lo que entendemos por sociedad y comunidad, las tradiciones sociológicas del aristotelismo comunitario o cooperativo y el individualismo iusnaturalista que han dado lugar a numerosas teorías contrapuestas ${ }^{\prime}$. Pero también se destacan intentos de aunar ambas tendencias. Desde quienes, adhiriendo a una 
dinámica de la teoría antropológica evolucionista, consideran que la modernidad arrasará con la comunidad, pasando por quienes abogan por un cambio social cíclico, hasta quienes ven la necesidad de definir un modelo compensatorio en el que coexistan ambas realidades.

\section{RECONOCIÉNDONOS DESDE LOS ORÍGENES}

Entre los antecedentes del Trabajo Social Comunitario en el ámbito internacional reconocemos las acciones de Organización Comunitaria emprendidas por Robert Owen dentro del movimiento comunitario laico representado por la New York Society for Propagating Communities. Para algunos, desde un modelo utópico, aunque sin olvidar que, situado en un marco reformista, Owen pretendió contraponer un sistema cooperativista al modelo de las ciudades industriales del capitalismo. Sus premisas eran que la «comunidad pura» encontraría las formas para influir sobre el ambiente que moldeaba el carácter del hombre. Lo fundamental era la dignidad humana y la independencia de las personas alcanzada a través de la ciencia, la razón y la educación. Concibió un plan de comunidades rurales autogestionadas con sistemas educativos y culturales. El owenismo representó un movimiento de gran popularidad en Estados Unidos entre los años 1821 y 1828.

Posteriormente, Mary Richmond, en The Interrelation of Social Movements (1910), destacó la importancia del trabajo comunitario, viendo la trascendencia de los movimientos sociales y su capacidad para colaborar en la formulación del diagnóstico de las ciudades donde se trabajaba. La primera conceptualizadora del Método de Trabajo Social aboga claramente por la importancia del entorno social.

Roger Baldwin es quien aparentemente, por primera vez, hasta donde las investigaciones existentes señalan, utiliza en un documento oficial la denominación de Organización de la comunidad, destacando la trascendencia de la planificación del trabajo comunitario, durante la Primera Guerra mundial y su postguerra

Digamos que éstos son, junto con el movimiento de los establecimientos de los Barnett, algunos de los orígenes primigenios del Trabajo Social con la comunidad, pero nos interesa destacar los que podemos encontrar en nuestro país. Así, consideramos que existen interesantes ejemplos del enfoque comunitario que fueron llevados a cabo en el te-

1 Desde el Trabajo Social no se puede obviar el hecho de que las Políticas Sociales de determinados posicionamientos políticos y filosóficos, y, en este sentido, el individualismo y el colectivismo nos brindan claros ejemplos de ello, por eso nos parece importante invitar a la reflexión sobre estos temas. 
rritorio español durante la década de los 60 y 70 .

Es indudable que la incorporación de España al seno de la, ahora, Unión Europea, ha conllevado la adquisición de nuevas filosofías de trabajo en el campo de lo social. Nos parece, sin embargo, que resulta necesario recurrir a las propias fuentes empíricas, y a realizar comparaciones sobre lo hecho hasta el momento y las nuevas propuestas de intervención. Parece importante asumir que el conocimiento en materia social es acumulativo y que las verdaderas conceptualizaciones no consisten en cambiar el nombre a lo que se venía haciendo. En tal sentido, entendemos que recuperar para el análisis de la intervención comunitaria ejemplos como el Plan Social Baza, desarrollado por Cáritas en los años 60 , así como tantas otras experiencias similares de esa época, nos permitirá abordar con mejores herramientas de estudio los desafíos que nos imponen los nuevos tiempos en el ámbito de la intervención comunitaria.

Las experiencias como tales son irrepetibles, porque, como bien sabemos responden a un determinado contexto histórico, a un marco temporoespacial específico. Sin embargo, analizar lo realizado nos permite ver cómo, al claro objetivo de modernización que en aquel contexto se buscaba, se pudo incorporar la permanencia y desarrollo del espíritu comunitario. Esta característica pareciera desprenderse, para nuestro análisis, de la realización de un Trabajo Social no burocratizado y atento al proceso que implica la intervención social en el ámbito comunitario.

Son estas observaciones las que nos interesa retomar a la hora de entender cómo es posible conciliar dos aspectos que desde la formulación teórica se presentan como aparentemente contradictorios y que, sin embargo, las experiencias habidas, nos demuestran que son de posible y deseable convivencia.

\section{EL CONTEXTO FINISECULAR DEL TRABAJO SOCIAL COMUNITARIO. TIEMPO DE BALANCES}

La llegada de un nuevo milenio ha dado pie para el debate reflexivo (aunque no siempre) sobre los problemas sociales y las formas de intervención en la realidad social. El Trabajo Social no podía permanecer ajeno a esta circunstancia y ello ha quedado evidenciado en los títulos de numerosos artículos y convocatorias a Congresos, Jornadas y Seminarios.

En este escenario de fin de siglo resulta evidente, desde la perspectiva del Trabajo Social, que, a pesar de los avances y progresos en 
diversos ámbitos vinculados al desarrollo (económico, científico, techológico y social), persisten y se recrean nuevas formas de pobreza y situaciones de desigualdad.

En este sentido, podemos decir que en las cuestiones sociales todo tiempo pasado no ha sido necesariamente peor o mejor, sino que cada momento requiere un análisis desapasionado en la lógica y apasionado en la búsqueda de las mejores alternativas.

La globalización (o mundialización) con su consiguiente característica de multidimensionalidad, no pasa inadvertida en cualquier análisis sobre cuestiones de nuestros días. Anthony Giddens afirma «puede que globalización no sea una palabra particularmente atractiva o elegante. Pero absolutamente nadie que quiera entender nuestras perspectivas en este fin de siglo puede ignorarla» (Giddens, A 2000: 19-20). Así, basta con que recorramos las publicaciones de los últimos cinco años para observar cómo el discurso se ha visto plagado de referencias a lo que MacLuhan definió como la «aldea global». A partir de asumir la realidad de su omnipresencia interesa realizar un «intento de análisis» de lo que implican el discurso sobre la globalización y sus repercusiones en los temas inherentes al Trabajo Social, y particularmente al Trabajo Social con la Comunidad.

En primer lugar, consideramos que el discurso de avances tecnológicos y la entrada en la sociedad de la información son realidades tangibles (de manera real y no virtual) sólo para una pequeña parte de la población mundial. Al decir tangibles nos referimos a que sólo una parte de la población mundial se beneficia en forma directa de ellas, sintiendo más sus ventajas que las nuevas desigualdades que se generan en quienes no pueden acceder a ellas. Al mismo tiempo, es cuantitativamente mayoritaria la permanencia $-\mathrm{y}$ en muchos casos el incremento- de situaciones de desigualdad. El incremento se acentúa cuando las condiciones de inaccesibilidad a determinados bienes, o a la formación y a la información, dependen del manejo de herramientas como pueden ser, desde el poseer una línea telefónica hasta el saber cómo realizar una gestión a través de Internet sin necesidad de desplazarse $^{2}$. Digamos que lo que hemos dado en llamar el «efecto Mateo» ${ }^{3}$

2 Al respecto resulta de interés consultar la entrevista publicada por RTS Revista de Treball Social, número 146, junio de 1997, pág. 128 a 137 a Joan Majós (ex-ministro español de Industria y consejero responsable del área de las industrias de la información y las telecomunicaciones en la Comisión de la Unión Europea) donde adjudica un importante papel al Trabajo Social en la preparación de las personas para el mundo de las nuevas Tecnologías. "Deberian actuar (los profesionales del Trabajo Social) en la' implementación de políticas de preparación de la población para extraer el máximo beneficio posible de todos esos cambios y para evitar nuevos riesgos. (...) Todos apren- 
adquiere velocidades cibernéticas y éste es un punto que debe mantenernos alerta desde el Trabajo Social. Las metamorfosis que se producen en las relaciones laborales van dejando fuera del mercado a una gran cantidad de personas, lo que equivale a condenarlas a situaciones que oscilan entre la vulnerabilidad y la marginalidad. Las relaciones cotidianas y los vínculos personales también van sufriendo paulatinamente transformaciones debido al avance de los aspectos de la llamada era de la información.

Es indudable que existen también aspectos positivos en los avances acaecidos en este siglo que termina. Los avances tecnológicos han permitido incorporar al mercado laboral a un buen número de personas con discapacidad que no podrían hacerlo de otra manera. Un alto porcentaje de mujeres pareciera verse beneficiado también, al menos en algunos países, por las virtudes del teletrabajo ${ }^{4}$. Sin embargo, lo importante es que la balanza se incline de manera proporcional a la hora del reparto de oportunidades, para evitar la pérdida de las condiciones reales de equidad. Vemos entonces que la prevalencia de factores societarios de modernización y confort puede dar lugar a un resquebrajamiento de estructuras esenciales para el desarrollo de una comunidad. Al referirnos a esenciales no estamos haciendo una valoración, sino simplemente constatamos un hecho de la realidad, dado que hay ciertas condiciones sine qua non para la existencia de la comunidad tal y como ha sido definida por la Sociología.

En segundo lugar, observamos que existe una tendencia a homologar globalización con nueva economía, hecho que ejemplificamos sirviéndonos de una cita hecha por nuestra colega Concepción Fernández Alvarez en las ponencias del II Congreso de Trabajo Social de la Comunidad de Madrid. En esa oportunidad, citó la definición dada en varios documentos del Banco Mundial que conceptualiza globalización como un cambio general que transforma la economía mundial «que se refleja en vinculaciones internacionales cada vez más amplias e intensas del comercio y las finanzas» (Ponencias del II Congreso de Trabajo Social en la Comunidad de Madrid, 2000:100). Es indudable que lo económico involucra muchísimas variables, pero cuando hablamos de «tendencia a definir globalización desde el campo de lo económico»

derán a teclear, pero no a utilizar lo que esas teclas proporcionan, y aqui es donde, los que estáis en el mundo del trabajo social, os encontraréis con personas a quienes la escuela no ha preparado y se les tendrá que enseñar" (pág. 134).

3 En cste concepto me hago deudora de la definición que daba Demetrio Casado en El bienestar social acorralado, Madrid, Promoción Popular Cristiana, 1986.

4 España es el país de la Unión Europea con el porcentaje más bajo de personas dedicadas al telctrabajo. 
queremos decir que, si bien existen numerosas voces que hablan de otros aspectos, mayoritariamente se describen en este contexto los netamente económicos.

Alain Touraine afirma que "globalización es una palabra puramente ideológica. Supone una relación necesaria entre varias tendencias sumamente importantes, pero no directamente relacionadas. Lo que se llama globalización es en realidad un proceso de diferenciación de varias dimensiones de la vida colectiva" (Touraine, A. 1998:32). En este sentido, adherimos a la definición de globalización que incorpora una multitud de fenómenos que no sólo se relacionan con el mundo de la economía, sino que involucran otra serie de ámbitos en cuyos campos interviene de manera directa el Trabajo Social.

Estos otros ámbitos de la «globalización», traen implícitos cambios en la vida cotidiana, que repercuten de manera inevitable en las relaciones sociales, quizá con mayor fuerza, o al menos mayor impacto, a la hora de hacerse visibles, que otros cambios que pudieron darse en anteriores etapas de la historia. En ellos centramos nuestro análisis porque allí encontraremos los desafíos del Trabajo Social con la comunidad.

Al poner el acento sobre la tendencia a definir el fenómeno de la globalización desde perspectivas económicas, creemos encontrar un ejemplo del proceso de predominio ideológico de los aspectos societarios, es decir, inherentes a las relaciones secundarias donde el objetivo es obtener un determinado fin. En esta línea, queremos someter a debate la contradicción que en principio pareciera existir entre un Trabajo Social inserto en el siglo XXI, en un mundo globalizado y al parecer netamente societario, con la utilización metodológica de los criterios comunitarios. De esta manera sostenemos la tendencia de la globalización (modernidad+postmodernidad) como refuerzo de los aspectos societarios, en tanto que lo comunitario permanece en un ámbito previo a lo moderno.

Sin embargo, en este caos ordenado, es un hecho que ambas instancias coexisten con mayor o menor éxito. Pareciera además que su coexistencia es necesaria para las personas, y por tanto buscada. De lo que trataremos es de cómo definir qué papel le compete al Trabajo Social con la Comunidad en este contexto.

Con oportunidad de la entrega del premio Príncipe de Asturias de Humanidades a Umberto Eco, circuló en los medios de comunicación una frase suya que dice «en Francia se teme la mundialización que impondrá el inglés. A lo mejor ocurre lo contrario, el modelo del 
milenio será San Pablo, que nació en Persia en una familia judía, que hablaba griego, leía la Torá en hebreo y vivió en Jerusalén donde hablaba arameo. Cuando se le pedia el pasaporte era romano. Es un ejemplo interesante de mundialización».

El fin de una etapa siempre impone un balance. Entre quedarnos con el debe y el haber nos parece más interesante la posibilidad de una tercera opción ${ }^{5}$ de transformación de unos en otros, que serán novedosos y distintos a sus orígenes. En este marco de las sociedades complejas, cabe preguntarnos entonces por el papel que desempeña el Trabajo Social con la comunidad y sus posibles nuevas formas de intervención en el contexto del siglo XXI.

La respuesta a este interrogante constituye un imperativo ético en tanto que, si nos planteamos la responsabilidad de avanzar en la consolidación de la profesión, es preciso identificar las claves con que se mueve la realidad social. La correcta concepción de la relación entre el enfoque comunitario y la modernidad (y la postmodernidad) podrá facilitar el diseño de nuevas formas de intervención «sustentables» ${ }^{6}$.

¿Será posible conciliar los avances de la técnica, el progreso y el desarrollo económico con el desarrollo humano y social? ¿Existirá un ámbito que haga factible el respeto de las necesidades humanas y del medio ambiente? ¿Quedará un papel para la intervención a través del Trabajo Social Comunitario en una sociedad que enarbola como bandera el individualismo?

\section{COMUNIDAD Y SOCIEDAD EN TIEMPOS DE LA GLOBALIZACIÓN}

El marco de la globalización parece siempre visualizado desde un análisis propio del pensamiento binario, casi podríamos decir filosóficamente maniqueo, porque discurre pendularmente entre lo bueno y lo malo según quién lo describa. Para nuestro análisis existe una tercera opción posible. Es la que vincula ambos aspectos para dar lugar a una nueva situación. Desde nuestro criterio, esta tercera opción se ejemplifica en las palabras de la profesora Natividad de la Red quien señala que las actuales transformaciones provocadas por los «procesos de fragmen-

5 Recordamos que J. Galtung siempre plantea la necesidad de evitar las polarizaciones buscando una tercera posibilidad en las situaciones de conflicto, así lo sugiere desde el propio título de una de sus obras: Hay alternativas.

- Utilizamos el término como una adaptación a lo que nos interesa considerar en el Trabajo Social Comunitario, de modo que las formas de intervención no "destruyan" los recursos que las redes sociales primarias brindan. 
tación social, provocan que los sectores impactados por los procesos de exclusión tiendan a organizarse en el contexto local a través de experiencias comunitarias compartidas». (De la Red, N. V ${ }^{\circ}$ Congreso Estatal de Intervención Social.) Es evidente entonces que de situaciones que apriorísticamente son susceptibles de ser definidas como negativas, pueden surgir también alternativas novedosas desde el ámbito de la comunidad.

Todas estas transformaciones que se inician con la Ilustración y la modernidad, y que continúan en la postmodernidad actual, parecieran tener un saldo negativo para las relaciones sociales de tipo comunitario. Sin embargo, es igualmente visible la creciente «pre-ocupación»-que en muchos casos se transforma en «ocupación»-por los diversos problemas sociales y sus posibles formas de resolución. En este sentido son de analizar, por su interés y repercusión sociológica, los movimientos sociales que reivindican una vuelta a los «valores comunitarios». Así, nos encontramos con las revueltas habidas en la Cumbre de Seattle, los planteamientos del filósofo Zearzan, los movimientos ecologistas que fundamentan la necesidad de un desarrollo sustentable, las proclamas de José Bové en Francia enfrentándose a los aspectos considerados como más negativos de la globalización... Todos estos hechos demuestran que existe por parte del hombre y la mujer modernos una necesidad interna de conciliar los muchos beneficios societarios de la modernidad con otros aspectos a los cuales no se ha podido dar respuesta y que repercuten en las relaciones interpersonales.

La caída de los grandes arquetipos en términos de organización social ha traído como fruto una sensación de incertidumbre en cuanto a las formas de alcanzar el bienestar de las personas. La información transmitida de forma masiva e indiscriminada, y respondiendo en todos los casos a intereses no manifiestos, produce en muchos casos más confusión que elementos de análisis.

Citando nuevamente a Touraine "En el mundo entero, y ese es mi concepto de la globalización, los individuos están tratando de buscar una solución al mismo problema: cómo combinar esta participación del mundo que llamamos de racionalidad instrumental, con la defensa de la cultura, de la personalidad. Esto es nuevo y no existe la bipolaridad de antes (...). Todos los grupos sociales -y desde categorías sociales, étnicas, religiosas, sexuales-están tratando de buscar una respuesta particular a un problema de tipo general que es la combinación, no de racionalidad e irracionalidad, sino de racionalidad instrumental, de técnica y mercados, con identidad cultural" (Touraine, A.1998: 32). El texto nos parece absolutamente ilustrativo de la realidad del Trabajo Social de enfo- 
que comunitario. La necesidad de conciliar dos realidades que, si bien en apariencia son contradictorias o, al menos, conceptualmente son definidas como contradictorias, requieren ahora de una necesaria convivencia cooperativa. No podemos hacer determinadas cosas si carecemos del apoyo de la comunidad, pero al parecer lo que queremos hacer es un objeto societario. Es decir, hemos pasado de hablar de realidades contrapuestas a hablar de realidades concéntricas que a la vez requieren un intercambio entre sí para lograr sus respectivos objetivos. Esto tiene también su correlato en el Trabajo Social y de ahí la importancia en plantearse desde la ética las formas de intervención.

Los discursos marcan las tendencias, pero el Trabajo Social ha de concebirse desde una responsabilidad profesional, planteándonos por qué intervenimos en un determinado momento y de una manera dada y analizando si existe coherencia entre nuestro discurso y nuestra actuación.

\section{EL TRABAJO SOCIAL COMUNITARIO DEL SIGLO XXI}

En este contexto que hemos descrito se enmarca la realidad del Trabajo Social comunitario del siglo que se inicia. Un contexto en el que todos asumimos el discurso de los grandes cambios y de las grandes velocidades, de las nuevas tecnologías, pero, a la vez, reclamamos la necesidad de determinadas estructuras que concilien nuestro "bienser" (Rodríguez Villasante, T. 1998:55) con nuestro "bien-estar" (comunidad-sociedad).

Nos interesa «aterrizar» los conceptos y apreciaciones teóricas que hemos analizado en la realidad de la intervención del Trabajo Social.

Existen diversas formas de intervención que, si bien todas pueden situarse bajo el paraguas de «enfoque comunitario», unas parecen favorecer las relaciones comunitarias y otras mucho más las societarias. Ante un primer análisis, podemos decir que se detecta una mayor proporción de intentos conciliadores -al menos en el discurso- entre la sociedad y la comunidad, que excluyentes, es decir, plantearse la comunidad como impuesta a la sociedad o viceversa. Pero no parecería riguroso para el análisis obviar que, en muchos casos, si bien hablamos de Trabajo Social Comunitario, las acciones encaradas desembocan por fuerza en criterios societarios. Ejemplos de esta circunstancia podemos encontrarlos en proyectos de desarrollo donde se capacita a una población para desempeñar ocupaciones que encontrarán salida fuera de su ámbito territorial. En el campo de la cooperación al desarrollo, también pueden encontrarse ejemplos de traspolación de experiencias en que la 
idea del "desarrollo comunitario" albergó un espíritu modernista. Llevar civilización a los pueblos del tercer mundo para lograr un mayor grado de bienestar. El problema fue que en muchos casos no se respetaron las redes naturales, los vínculos comunitarios y se aplicó exclusivamente el "espíritu societario y modernizador". En el camino perdimos el "bien-ser", y, lo peor del caso, es que no llegamos tampoco al "bienestar".

Es indudable que la utilización del enfoque de intervención comunitaria con fines político-partidarios (sin que estos fueran claramente explicitados) ha estado presente en no pocas oportunidades. Este hecho encuentra una mayor posibilidad de desarrollo en los momentos en que no existe una libertad política y, por tanto, la acción social es una de las posibles vertientes por las que se desenvuelven las inquietudes y reclamaciones políticas. En definitiva, el origen del desarrollo comunitario y la organización de la comunidad han respondido a circunstancias políticas. Es decir, que puede darse el caso en que el objetivo primigenio de la «comunidad» quede subsumido o disfrazado detrás de otros objetivos.

El discurso profesional de los años 70 no se concebía sin el trabajo social comunitario con claras connotaciones ideológicas. Esto respondía a una realidad histórica, y a una situación política. El trabajador social de la época era considerado un agente de cambio, que, como bien describe el profesor Barbero, «toleraba malamente el reformismo propio de la profesión», por lo que, decimos nosotros, renegaba de su propio origen.

Por aquel entonces lo comunitario era sinónimo de agitación, movilización, organización (Marco Marchioni). En América Latina también se vivió este proceso con la Reconceptualización ${ }^{7}$ en cuyos textos abrevó buena parte de la generación de Trabajadores Sociales españoles que abogaban por el Trabajo Social Comunitario.

Lo importante es que de todas estas experiencias podemos ir sacando aprendizajes enriquecedores que nos sirven para no repetir $-\mathrm{o}$ al menos intentarlo- los mismos errores.

7 El problema de la utilización de conceptos políticos insertados en el discurso profesional demostró en muchos casos una escasa validez metodológica a la hora de ser traducido a hechos concretos, en el campo, claro está, del Trabajo Social. Con esto consideramos que, muy lejos de deslegitimar la incorporación de valores propios del pensamiento político, lo que queremos es evitar la confusión que arrastramos hasta en la conceptualización de lo que es el Trabajo Social. Muchos de los teóricos de la reconceptualización reconocen que, sin dejar de afirmar los efectos movilizadores y revitalizadores que ésta ha tenido, su validación en la práctica terminó resultando escasa. 
Ahora bien, lo comunitario dejó de estar presente en el discurso del Trabajo Social español pasada la década de los 70. ¿Por qué?

Es importante tener en cuenta que convergieron varios factores. Por una parte, nos parece necesario señalar que la situación de desarrollo económico en que fue ingresando España, fruto, por una parte, de las divisas que ingresaban los emigrantes (que a la vez contribuían al descenso del desempleo), por otra, el crecimiento económico con una fuerte demanda de mano de obra en la industria y servicios, y también indudablemente por los ingresos habidos con el turismo. En definitiva, no interesaba la intervención comunitaria para solucionar problemas que se canalizaban desde la perspectiva individual. En muchos pueblos españoles se vivió la paradoja de que aquéllos que habían sido promotores de cooperativas y verdaderos líderes y artífices del desarrollo comunitario se retiraron de su acción comunal para refugiarse en empleos en las grandes urbes que en nada se equiparaban a la trascendencia de su labor en sus lugares de origen ${ }^{8}$. Porque la modernización del conjunto de la sociedad necesitó ocultar lo comunitario y, en términos de prácticas profesionales, nos atrevemos a decir que «lo arrasó». Una sociedad de claras características rurales, con el lastre de una larga dictadura que le había dejado fuera del contexto internacional y que, por ello mismo, le había asignado una serie de tópicos, necesitaba forzosamente hacerse de una nueva imagen, obviamente lo más moderna que fuera posible. El «600» fue el símbolo para España, de una modernidad que traía aparejada la burocratización y la complejización de las relaciones sociales. Era el progreso que permitía una mayor movilidad social, que auguraba tiempos distintos.

Antes hemos hablado de la complejidad de la realidad social y por ello, del mismo modo que el trabajo comunitario desapareció del discurso durante los años 80, aparecieron los Servicios Sociales y la red pública de Servicios Sociales. En tal sentido, el profesor Octavio Vázquez Aguado afirmaba recientemente «existe una íntima relación entre la disciplina y la sociedad en que se desarrolla» (Vázquez Aguado 2000).

El nuevo paradigma trae aparejado una mayor conceptualización desde el punto de vista teórico, lo que lleva a una mayor tecnificación de la intervención. Sin embargo, en muchos casos, el resultado termina

\& Para esta afirmación me sirvo de las anécdotas que al comentar este artículo me hiciera Demetrio Casado sobre lo ocurrido en el pueblo de San Pedro de Gaíllos (Segovia), donde destacados dirigentes de los procesos de desarrollo comunitario se trasladaban a Madrid para trabajar como asalariados en labores que se encontraban muy por debajo de la trascendencia y el status social de las tareas que desarrollaban en su pueblo. 
siendo una creciente burocratización ${ }^{9}$. Esto se corresponde con aquello que el propio Max Weber definió como un fenómeno propio de la modernidad, y el Trabajo Social, que, por definición conceptual, se encuentra directamente vinculado con el contexto histórico, político, económico y axiológico en que se desarrolla, también se vio influido en su discurso por este proceso de modernización.

Interesa también recordar lo que el profesor Barbero describe como las dos lógicas en el discurso del Trabajo Social:

1) la lógica de los servicios, que responde a la estrategia de la autoafirmación y a la del desarrollo de la red de Servicios Sociales, $y$

2) la lógica de los proyectos (actual), que responde a la estrategia de la vertebración. El Trabajo Social asume un papel de mediador, concertador, partner, gestor, ingeniero social.

Cabe, de todos modos, incorporar a este planteamiento el criterio de hasta qué punto estas lógicas son asumidas desde la profesión y son dirigidas y consolidadas con total conciencia, o pasan por ser admitidas desde la práctica cotidiana como una realidad inapelable. Coincidimos plenamente en que, cuando menos, es necesario analizar de qué manera los discursos se van consolidando y cómo desde el discurso se afirman determinadas formas de intervención. No en vano, cuando el Trabajo Social Comunitario ha sido una de las formas pioneras de intervención del Trabajo Social, actualmente pareciera haber cedido su protagonismo a la Psicología Comunitaria, a punto tal que los insumos teóricos utilizados para el estudio del Trabajo Social con la comunidad en muchos casos se nutren mayoritariamente allí, olvidando por completo el propio acervo de la profesión.

En este sentido, nos permitimos incorporar otra variable de análisis al enfoque de las dos lógicas propuesto por el profesor J.M. Barbero, y es el de la influencia que las políticas y formas de intervención de la Unión Europea han tenido en el Trabajo Social.

La lógica de los proyectos responde a una realidad político-económica que se ha instalado en la intervención social. La influencia que los proyectos financiados por la Unión Europea ha establecido sobre el Trabajo Social español es motivo de muchos debates. Existen muchos aspectos de gran importancia, como la construcción de redes europeas, la transferencia de tecnologías y la consolidación de un espacio y len-

9 En su artículo La Burocratización de los Servicios Sociales (UCM, 1993), la profesora Encarna Guillén Sadaba da un certero panorama de lo que implicó este proceso de burocratización para la actitud del estrato profesional del Trabajo Social. 
guaje común en los aspectos sociales ${ }^{10}$. Pero resulta, a nuestro criterio, necesario reconocer que lo hecho anteriormente en el campo de la intervención comunitaria tuvo un valor intrínseco merecedor de ser rescatado y revalorizado. No se trata de una adhesión melancólica, sino de la incorporación de un dato de análisis de la realidad que permita trabajar en el presente del Trabajo Social con la comunidad desde una mejor perspectiva.

La incorporación de pleno derecho en la Unión Europea trae aparejada la aparición de un nuevo lenguaje. Estamos ante lo que ha dado en llamarse el discurso del proyecto, territorialidad, partenariado, multidimensionalidad. Se redimensionan totalmente las formas de intervención. En palabras de Castells estamos ante una nueva cuestión social: la quiebra del estado de bienestar.

Esto implica la toma de conciencia sobre un nuevo concepto que emerge y se reproduce rápidamente el de "vulnerabilidad social", la toma de conciencia por parte de amplias capas de la población de la posibilidad de pasar a incorporar las filas de la que ha dado en llamarse "Nueva Pobreza", modifica rápidamente el contexto en el que se mueve el Trabajo Social.

En este análisis, resulta preceptivo destacar que esta definición corresponde a aquellos países occidentales donde la cultura salarial y la sociedad del bienestar han constituido una realidad palpable, porque en muchos países, de los que, por ejemplo, podríamos citar los llamados "emergentes", este proceso es vivido de manera inversa.

Cuando analizamos las variaciones en el discurso del Trabajo Social podemos ver dónde se sitúa la intervención comunitaria. Hemos de considerar en qué contexto hablamos de la intervención comunitaria. No podemos olvidarnos que los inicios del Desarrollo Comunitario tuvieron una neta carga política.

Insistimos en la importancia de sistematizar los ejemplos de intervención comunitaria que se han dado en nuestro país, como las experiencias de Baza y las habidas en Bésos y tantas otras dentro de nuestro país que supieron aglutinar los aspectos de modernidad y comunidad. También nos parece importante citar un ejemplo de las experienicas que se dan más allá de nuestras fronteras, aun en aquellas culturas que en principio parecieran totalmente diversas a la nuestra. Un modelo de

10 Al respecto del lenguaje, nos parece de sumo interés el análisis realizado por Demetrio Casado sobre el impacto de los Programas Europeos de Lucha contra la Pobreza en la bibliografía española. "Aproximación al impacto de los progranas antipobreza CE/UE en la bibliografía española" en Revista de Políticas Sociales en Europa $N^{\circ} 4$, septiembre de 1998 , p. 139 a 149. 
enfoque de desarrollo comunitario como el propuesto por el economista Yunus con la creación del Grameen Bank en Bangladesh nos demuestra que la integración social a través de los aspectos económicos (tan en boga en la intervención social de nuestros días) requiere de un concienzudo conocimiento de las estructuras sociales en las que se interviene.

Muhamad Yunus inicia su labor en 1976 en la aldea de Jobra. Toma conciencia de que a las personas sin tierra les resulta prácticamente imposible obtener préstamos en bancos comerciales porque no podían presentar avales. Decide entonces avalar personalmente los préstamos de los más pobres y consigue coeficientes de amortización superiores al $99 \%$. En 1983 el proyecto se convirtió en un banco de pleno derecho. El gobierno de Bangladesh aportó el $60 \%$ del capital amortizado inicial. En 1991 el banco había ampliado sus servicios a más de 23.000 aldeas a través de sus casi 900 sucursales. Aproximadamente un millón de hogares había recibido créditos. El promedio de préstamos es de 60 dólares y el tipo de interés (16\%) no contiene ningún tipo de subsidio. Los préstamos, que se destinan fundamentalmente a la compra de materias primas y equipamientos, han generado mucho empleo, especialmente entre las mujeres rurales.

Los prestatarios también han de añadir una taka (moneda nacional) por semana a su cuenta de ahorros. En 1991 este fondo de ahorros obligatorio había acumulado 962 millones de takas: el 62\% de los préstamos pendientes (información del PNUD, 1993). Curiosamente, contamos con información que dice que el modelo no ha podido ser exportado con igual éxito a otras regiones (estudio de J.J. Thomas, 1995 PREALC; y de Hulme, 1993 para Asia -Malasia y Malawi-).

Consideramos que el proyecto del Grameen Bank es un proyecto claramente societario, donde no existen aspectos censurables, pero donde el enfoque de desarrollo comunitario está directamente vinculado a un factor de acceso a la modernidad y a las posibilidades de expansión a través del trabajo de las personas. Nada nos cuenta de la realidad de esas comunidades en cuanto a las posibilidades de una mayor solidaridad entre las personas o de tejido social.

No hemos de olvidar que el enfoque de los microemprendimientos o microempresas tiene un gran arraigo en los enfoques del desarrollo y es también un concepto muy desarollado como estrategia de desarrollo local, por ello nos ha parecido importante citar este ejemplo.

Podemos decir entonces que:

- El proyecto es altamente positivo como elemento de redistribución de riqueza. 
- Es una estrategia claramente democratizadora porque permite el acceso al crédito a personas que habitualmente carecen de él por su condición socioeconónomica.

- No tiene un enfoque en que lo comunitario como tal sea la prioridad, sin embargo, existe un respeto por pautas de relación propias de la comunidad en que se implantan.

- El enfoque se basa en lo societario, sin embargo, concilia lo comunitario en una realidad en la que esta alianza se supone particularmente difícil.

\section{A MODO DE EPÍLOGO}

En todo caso, de estas primeras reflexiones en voz alta se desprende la imposibilidad de lograr un equilibrio social (comunidad) sin un progreso económico (sociedad-modernidad), pero lo que a la vez también ha quedado demostrado para nuestro análisis es que el enfoque exclusivamente modernista no alcanza a cubrir la totalidad de la realidad.

A la vez, inexplicablemente para los postulados economicistas, los grandes avances económicos no han llegado por igual a todos los sectores de la población, los beneficios del crecimiento continuo y las nuevas tecnologías se han quedado en manos de un porcentaje reducido de la población, e irremediablemente oímos una vez más el eco del «efecto Mateo».

Básicamente, el enfoque del desarrollo conlleva hoy en día la irrenunciable premisa de que no basta el crecimiento económico y la modernización tecnológica para enfrentar la pobreza. El Trabajo Social con enfoque comunitario debe destacar la necesidad de incluir mejoras en la distribución de los ingresos y, para ello, es también importante tener en cuenta los aspectos que hacen a las relaciones sociales primarias de las personas, así como el respeto de sus costumbres.

En este sentido, nos parece importante concluir que no pareciera correcto intentar conciliar sin más aspectos que en sí son definidos como contradictorios, tal como hemos visto que son comunidad y sociedad.

Antes bien, resulta necesario ver las formas alternativas de coexistencia de éstos que permitan intervenir creativamente desde el enfoque comunitario en Trabajo Social en una realidad social cada vez más compleja. 


\section{BIBLIOGRAFÍA}

BARBERO, J.M (1999): "20 años en los Discursos de Trabajo Social”, (19781998), pág. 9-41. Revista de Trabajo Social Servicios Sociales y Política Social $N^{\circ}$ 47. Madrid.

BADI, B. (1990): "Community, Individualism, and Culture" en Individualism, Theories and Methods, Birnaum y Leca (edits.), Oxford, Clarendon Press.

CASADO, D. (1970): Plan Social Baza, Ediciones Euramérica, Madrid.

CANALS, J. (1997) "Buscando al Trabajo Comunitario entre community y communitas: apuntes sobre unos conceptos importados" páginas 85 a 90 en Revista de Trabajo Social Servicios Sociales y Política Social No 40 .

DE LA RED, N. (1999): Mesa Redonda: Servicios Sociales Comunitarios redefinición de un modelo en transición. Perspectiva Rural, en CD.ROM V ${ }^{\circ}$ Congreso Estatal de Intervención Social "Calidad y responsabilidad compartida: retos del bienestar en el cambio de siglo", organizado por el Colegio Oficial de Psicólogos de Madrid y la Coordinadora Estatal de Intervención Social. Madrid, noviembre de 1999.

GIDDENS, A. (2000): Un mundo desbocado. Los efectos de la globalización en nuestras vidas, Editorial Taurus, Madrid.

GINER, S. (1985): Sociología. Editorial Nexos. Madrid.

GALLINO, L.: Diccionario de Sociología, pág 196. Siglo XXI Editores.

Ponencias y Comunicaciones Libres del II Congreso de Trabajo Social en la Comunidad de Madrid "Mirando hacia afuera". Editado por el Colegio Oficial de Diplomados en Trabajo Social y Asistentes Sociales de Madrid, noviembre de 1999.

RODRÍGUEZ VILLASANTE, T. (1998): Cuatro Redes para mejor-vivir, Editorial Lumen-Humanitas, Buenos Aires.

SOROKIN, P. (1986): Sociedad, Cultura y Personalidad. Su estructura y su dinámica. Sistema de Sociología General. Editorial Aguilar.

TOURAINE, A. (1998): revista El SEMANAL, 4 de octubre de 1998, entrevista de Mariano Aguirre, pág. 30 a 35. Madrid.

VÁZQUEZ AGUADO, O.: «Relaciones entre Trabajo Social y Sociedad» en Cuadernos de Trabajo Social 1999, 12:93-106, editado por la EUTS de la Universidad Complutense de Madrid. 